in vivo $34: 3127-3136(2020)$

doi:10.21873/invivo.12147

Review

\title{
Thyroid Dysfunction and Atherosclerosis: A Systematic Review
}

\author{
ANNA-MARIA PAPADOPOULOU ${ }^{1}$, NIKOLAOS BAKOGIANNIS ${ }^{1}$, \\ IOANNA SKRAPARI ${ }^{2}$, DIMITRIOS MORIS ${ }^{3}$ and CHRIS BAKOYIANNIS ${ }^{1}$ \\ ${ }^{1}$ First Department of Surgery, Laikon General Hospital, Athens, Greece; \\ ${ }^{2} 1$ st Department of Internal Medicine, Evangelismos General Hospital, Athens, Greece; \\ ${ }^{3}$ Department of Surgery, Duke University Medical Center, Durham, NC, U.S.A.
}

\begin{abstract}
Background/Aim: Thyroid dysfunction, both hypoand hyperthyroidism, has been associated with cardiovascular disease. The aim of this study was to evaluate the association between thyroid dysfunction and atherosclerosis measured mostly by carotid intima-media thickness, as well as discuss whether L-T4 replacement is able to reverse or slow down the progression of atherosclerosis. Materials and Methods: The review was conducted according the Preferred Reporting Items for Systematic Reviews and Meta-Analysis (PRISMA) guidelines. We performed on PubMed a literature search from May 2004 to January 2020, using the search terms 'subclinical hypothyroidism' or 'thyroid disorders' and 'carotid artery', 'carotid intima-media thickness (IMT)', 'levothyroxine', and 'atherosclerosis'. Results: Twenty-six studies were eligible and included in the analysis. Overall, the studies encompassed a total of 36.434 patients included in this review. Most studies indicated a proportional correlation between IMT and thyroid dysfunction. Levothyroxine (L-T4) replacement led to significant decrease of IMT after 1 year in most studies. Conclusion: Most studies have concluded that thyroid dysfunction is associated with arterial wall remodeling and, thus, with increased cardiovascular risk. However, the exact mechanistic background of pathological structural changes in the arterial wall is still unsettled. Large randomized controlled studies are required to definitively
\end{abstract}

This article is freely accessible online.

Correspondence to: Dimitrios Moris, Department of Surgery, Duke University Medical Center, 2301 Erwin Rd, 27710, Durham, NC, U.S.A. Tel: +1 2165716615, Fax: +1 9192063120, e-mail: dimitrios.moris@duke.edu

Key Words: Subclinical hypothyroidism, thyroid disorders, carotid artery, carotid intima-media thickness, levothyroxine, atherosclerosis, review. address the extent to which T4 replacement therapy might benefit patients with subclinical thyroid disorders.

Thyroid dysfunction has been associated with cardiovascular disease. Hypothyroidism and subclinical hypothyroidism $(\mathrm{SH})$, which is characterized by elevated thyroid stimulating hormone (TSH) levels and normal circulating free thyroid hormones, are independent risk factors for the pathogenesis of atherosclerosis and cardiovascular disease, affecting adversely the endothelial function (1-3). More specifically, they are correlated with i) high levels of low-density-lipoprotein cholesterol (LDL), ii) abnormal diastolic blood pressure, iii) low-grade inflammation and iv) hypercoagulability (4). On the other hand, hyperthyroidism, increases heart rate and pulse pressure and could affect arterial stiffness. L-thyroxine (LT4) and thyroid mimetics seem to benefit patients with atherosclerosis or metabolic disorders due to reduction of both serum total cholesterol and $\operatorname{LDL}(5,6)$.

Thickening of the arterial wall, as measured by the intimamedia thickness (IMT), can be used as a surrogate of cardiovascular disease, including myocardial infraction and stroke (1). The advantage of IMT is the ease of its calculation using ultrasound (7). Because of the high prevalence of subclinical thyroid dysfunction, it is important to clarify its effect on vascular atherosclerosis.

The aim of this review was to summarize the understanding of the association between thyroid dysfunction and atherosclerosis measured mostly by carotid IMT, as well as discuss whether L-T4 replacement is able to reverse or delay the progression of early atherosclerotic vascular wall lesions in SH patients.

\section{Materials and Methods}

The review was conducted according to the Preferred Reporting Items for Systematic Reviews and Meta-Analysis (PRISMA) guidelines. We performed on PubMed a literature search for the articles published from May 2004 until January 2020, using the 
search terms 'subclinical hypothyroidism' or 'thyroid disorders' and 'carotid artery', 'carotid intima-media thickness', 'levothyroxine', 'atherosclerosis'. Reference of these articles was scrutinized for additional relevant articles. Finally, reference lists of eligible studies were manually assessed in order to detect any potentially relevant articles ("snowball" procedure).

\section{Results}

Article selection and study demographics. The search strategy and the relevant results are illustrated in Figure 1. Following screening of titles and abstracts, 90 studies were retrieved for full-text evaluation. Twenty-six studies were included in the analysis. Overall, these 26 studies encompass a total of 36,434 patients included in this review.

Classification of thyroid status. The participants in the selected studies were classified into one of the following groups, based on their thyroid function tests.

i) Overt hypothyroidism, defined as high TSH concentration with a low free thyroxine (FT4) concentration;

ii) Subclinical hypothyroidism, defined as high $\mathrm{TSH}$ concentration with a normal FT4 concentration;

iii) Euthyroidism, defined as a normal TSH concentration with normal FT4 concentration;

iv) Subclinical hyperthyroidism, defined as low TSH concentration with a normal FT4 concentration;

v) Overt hyperthyroidism, defined as low TSH concentration with a high FT4 concentration.

Analytical measurements. The normal ranges of the thyroid hormones differed among the several laboratories. As discussed, Carotid intima-media thickness (C-IMT) was used as a surrogate of subclinical atherosclerosis and an effect of therapeutic interventions. European guidelines recommend that a C-IMT of $0.9 \mathrm{~mm}$ is accepted as the threshold above which atherosclerosis progression occurs (8). Similarly, the American Heart Association/American College of Cardiology Guidelines (9) also suggest C-IMT as a marker for cardiovascular risk assessment in asymptomatic adults at intermediate risk for $\mathrm{CV}$ disease (class IIa). An increase of $0.1 \mathrm{~mm}$ in the C-IMT is associated with a $10-15 \%$ increase in the risk of myocardial infarction and stroke (10). The IMT is defined as the distance between the media-adventitia and lumen-intima interfaces and is measured proximal to the origin of the carotid bulb using an IMT measurement software (11).

Arterial stiffness is a parameter which evaluates the mechanical properties of the vessel, while IMT assesses its structural properties. It is measured by stiffness $\beta$-index, which has been defined as the logarithm of the ratio of systolic to diastolic blood pressure divided by the fractional diameter increase during the cardiac cycle (12).
General principles. A relationship between thyroid dysfunction and vascular disease is not well-established. In one of the proposed theories, both overt and subclinical hypothyroidism can cause high LDL, diastolic hypertension, coagulopathy and myocardial dysfunction, thus conferring an elevated risk of atherosclerosis and vascular disease $(7,13,14)$. The lipid profile is an important causative factor for vascular remodeling associated with $\mathrm{SH}$. Most reports have documented a relationship between $\mathrm{SH}$ and a reversible atherogenic lipoprotein profile (6). Indeed, a remarkable difference of total cholesterol and triglycerides levels between SH patients and euthyroid individuals can partially explain this relationship (1, 15). Some pathophysiological mechanisms implicated to this finding could, firstly, include a high TSH triggering the expression of the hepatic 3-hydroxy-3-methyl-glutaryl coenzyme A (HMG CoA) reductase, which is a rate-limiting enzyme in cholesterol biosynthesis. In addition, triiodothyronine (T3) can influence HDL metabolism by increasing cholesteryl ester transfer protein (CETP) activity, which exchanges cholesteryl esters from HDL2 to the very low-density lipoproteins (VLDL) and TGs to the opposite direction (16). Furthermore, thyroid hormones stimulate the lipoprotein lipase (LPL), which catabolizes the TG-rich lipoproteins (17). Raised Lp(a) concentrations have been associated with the development of atherosclerosis and are viewed as a strong predictor of ischemic heart disease; thus, they are frequently assessed when studying thyroid disease. Current consensus supports that abnormal Lp(a) levels in $\mathrm{SH}$ patients are indicative of a genetic predisposition rather than a physiological effect of reduced thyroid hormone activity (6, 17). Recently, hyperhomocysteinemia has been proposed as another risk factor for atherosclerotic cardiovascular disease in the presence of clinically remarkable thyroid disease. This could be attributed to the fact that vitamin B12 and folateknown determinants of total homocysteine-deficiency is more frequently observed in overt compared to subclinical hypothyroidism. Thereby, it is possible that hyperhomocysteinemia results from vitamin deficiency rather than thyroid hormone deficiency (6).

Besides affecting cardiovascular risk factors, longstanding mild thyroid hormone deficiency can lead to structural changes in the arterial wall. Evidence from in vitro and animal model studies have demonstrated a remarkable effect of thyroid hormones to fibroblasts, especially in regards to collagen type I expression. Thyroid hormones might also downregulate collagen type I mRNA expression that in turn leads to inhibition of collagen biosynthesis. Moreover, thyroid hormones were shown to inhibit platelet aggregation induced by collagen. The reverse effect was observed in the deficiency of the hormones (18). On the other hand, thyroid hormones can affect vascular endothelial cells by modulating the expression of adenylyl cyclase and Ca21-ATPase, which affects the endothelium-dependent vasodilatation, contributing 
to a decrease in pulse wave velocity (PWV) (19). In the same frame, recombinant human TSH administration can acutely impair endothelium-dependent vasodilatation, possibly by inducing an inflammatory response and reducing nitric oxide (1). Similar changes can also occur during early stages of atherogenesis (6). Additionally, Mizuma et al. described the presence of iodothyronine deiodinase in human vascular smooth muscle cells. Given that thyroid hormones have been reported to relax vascular smooth cells directly, local production of $\mathrm{T} 3$ by iodothyronine deiodinase might be another vasolidative mechanism mediated by cAMP regulatory cascade (20). Of interest, in models of $\mathrm{SH}$ arterial wall alterations can be attributed to water accumulation and edema inside vascular smooth muscle cells in the arterial wall due the deposition of proteins in the extracellular space. An increased transcapillary escape rate for plasma proteins, such as albumin, has been reported in hypothyroid patients, as well as in animal models (1). These changes facilitate edema formation and probably explain the generalized edema and serositis in patients with myxedema $(1,6)$.

Finally, the process of autoimmunization progressively leads to local vasculitis and subsequently to the development of atherosclerotic plaques (2). More specifically, Hashimoto's thyroiditis can lead to low-grade chronic inflammation, which causes endothelial dysfunction (21). This could explain why thyroid hormone replacement and the consequent homeostasis in thyroid and lipid profile is not associated with a complete reversal of endothelial dysfunction. Also, chronic activation of the immune system due to autoimmunity is considered another mechanism inducing atherosclerosis $(22,23)$. Furthermore, the degree of autoimmunity has been associated with elevated cardiovascular risk (21).

Thyroid dysfunction and carotid artery atherosclerosis. There is a well-established connection between hypothyroidism and atherosclerosis. This has been demonstrated by several studies as illustrated in Figure 2. In particular, Peixoto et al. (15) have evaluated the association between SH and CIMT in 8.623 subjects and found it positive, even after adjusting for factors typically associated with IMT, such as cardiovascular factors. Median IMT was higher in SH subjects than in euthyroid ones $(p<0.0001)$. Tan et al. (24) have found that CIMT is higher in patients with subclinical and overt hypothyroidism than healthy controls $(p=0.042$ and $p<0.001$, respectively), concluding that there is a positive correlation between CIMT and TSH. They also found that high thyroglobulin levels were an independent factor that increased CIMT. Valentina et al. (25) have also elucidated the association between $\mathrm{SH}$ and carotid atherosclerosis, including 99 patients in their study and reporting similar results; patients with $\mathrm{SH}$ were found with a significantly higher mean CIMT compared to controls, despite the fact that maximum CIMT values were not statistically significant.
In the same vein, the authors showed that $\mathrm{SH}$ is related to higher CIMT and presence of carotid plaques, independent of classical risk factors for atherosclerosis. Likewise, Ghasemi et al. (26) have reported that SH patients had significantly higher mean IMT values $(p=0.01)$, along with elevated total cholesterol and triglyceride levels, compared to controls. In regression analysis, the mean IMT was negatively related to the T4 level $(p=0.02)$. Monzani et al. (6) have assessed the CIMT in $45 \mathrm{SH}$ patients at baseline and at six months in a setting of a randomized controlled study comparing L-T4 replacement to placebo. The mean IMT of $\mathrm{SH}$ patients was significantly higher compared to euthyroid controls $(p<0.001)$. A strong positive relationship between mean-IMT and serum TSH levels $(p=0.0008)$ was also noted. In accordance with this, Franzoni et al. (1) have measured the CIMT in 41 patients with SH. The etiology of SH was Hashimoto thyroiditis in all patients. They found that there was no difference in carotid diameter between $\mathrm{SH}$ and the control group; however, carotid artery data showed that IMT was higher in SH than in controls $(p<0.0001)$. Knapp et al. (2) have evaluated the correlation between SH and CIMT in 40 women with Hashimoto disease. They found that CIMT was higher in patients with SH compared to the controls (CCA right, $p=0.003$; CCA leFT, $p=0.001$; CA bulb right, $p=0.002$; CA bulb leFT, $p=0.014$ ). Despite these differences, none of the means met the European Society of Cardiology criteria of increased IMT. Bozkus et al. (13) have evaluated thyroid hormone levels in patients with an obstructive sleep apnea syndrome in order to determine the cardiovascular risk in these subjects. TSH levels were positively correlated to IMT $(p=0.002)$, while free T3 levels and IMT were negatively correlated $(p=0.001)$. Free T4 was not correlated to IMT. As a conclusion, the authors suggested that patients with obstructive sleep apnea should be screened for hypothyroidism considering the potential cardiovascular complications. Similarly, three more studies (27-29) have measured the CIMT in totally 221 subjects and found that it was significantly higher in patients with overt and $\mathrm{SH}$ as compared to the control groups. Two other studies $(16,30)$ have evaluated CIMT in pediatric patients with $\mathrm{SH}$ and concluded that it was significantly higher in the patient group compared to the controls. The patient group of the first study (16) was further categorized into two subgroups based on their serum TSH levels: i) patients with mild or moderate increases in TSH $(4.2 \pm 10 \mathrm{mIU} / \mathrm{l})$ and ii) patients with high TSH ( $\geq 10 \mathrm{mIU} / \mathrm{l})$. However, no significant difference was found between the two subgroups as far as CIMT is concerned $(p=0.610)$. In accordance to this, Sevuk et al. (31) have evaluated the effect of thyroid function and carotid artery plaque ulceration in 250 patients. The authors showed that $\mathrm{SH}$ and overt hypothyroidism were significantly more frequent in patients with ulcerated plaques $(p<0.001$ and $p=0.003$, respectively). Patients with ulcerated plaques also 


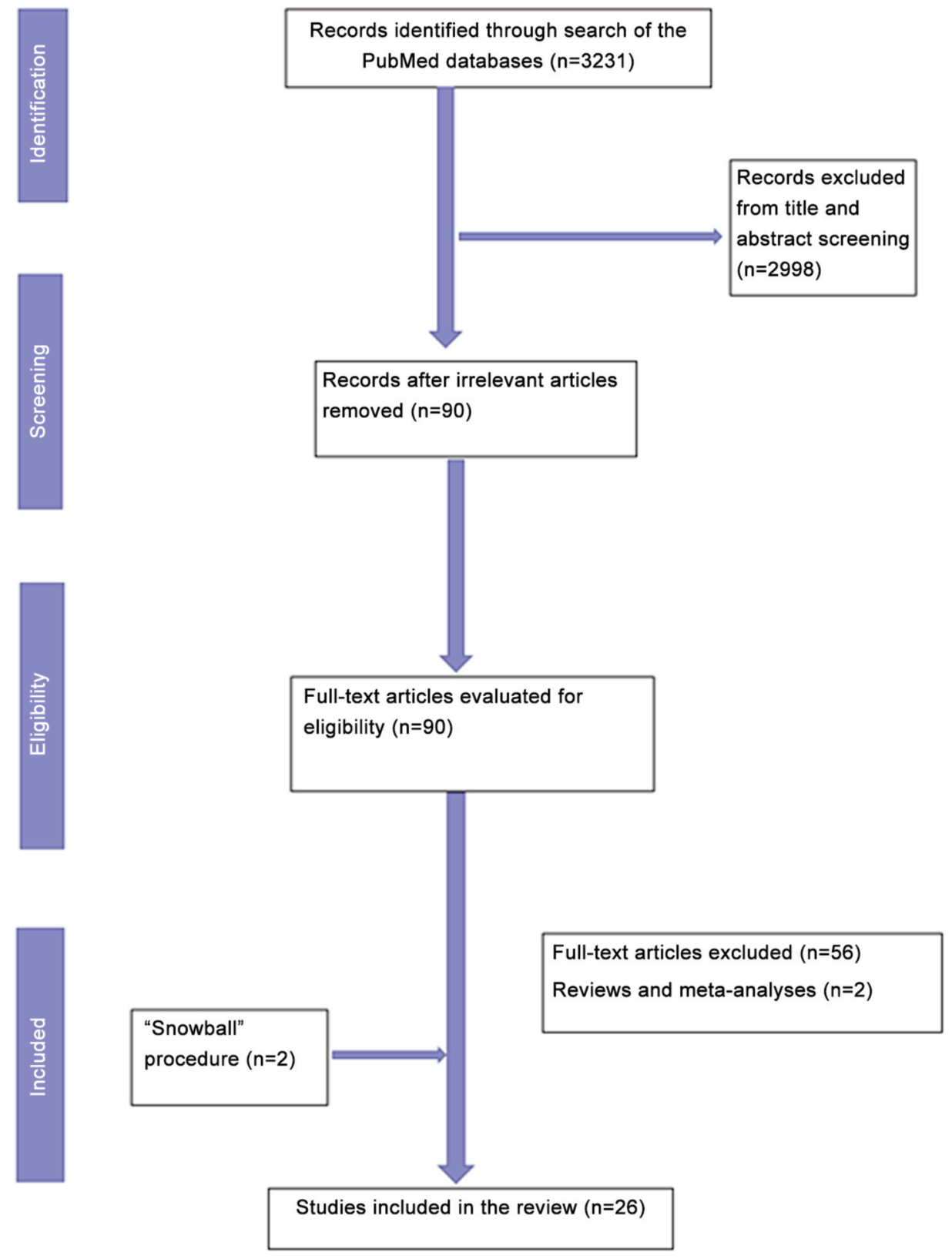

Figure 1. Flowchart of the search strategy.

had a significantly higher incidence of low-normal fT4 levels as well as elevated TSH levels compared to patients without ulcerated plaques ( $p=0.02$ and $p=0.001$, respectively). The authors suggested that $\mathrm{SH}$ and clinically symptomatic hypothyroidism could both be risk factors for plaque ulceration and subsequent cardiovascular events and that the thyroid function may be useful as an assessment, to stratify patients with internal carotid stenosis. Tian et al. (32) have examined the association between $\mathrm{SH}$ and carotid arterial stiffness in 183 subjects. B-index was detected significantly elevated in patients with $\mathrm{SH}$ as compared to normal controls ( $p=0.022)$. Nagasaki et al. (33) have also examined the effect of hypothyroidism on arterial stiffening and CIMT. Both arterial stiffness $\beta$-index and CIMT were significantly higher in the hypothyroid patients than in normal controls $(p<0.005)$. Jeong et al. (5) have studied 382 patients with reported ischemic stroke. Patients in the low-normal FT4 group (FT4: 11-12.3 pmol/l) had a significantly higher prevalence of internal carotid steno-occlusion (ICS) compared to the other normal (both TSH and f-T4) thyroid 
groups $(p=0.012)$. In addition, the percentages of ICS in the patients with subclinical hypothyroidism and those with low values of FT4 $(<11 \mathrm{pmol} / \mathrm{l})$ were similar to that of the lownormal FT4 group.

On the contrary, several studies have failed to show any correlation between $\mathrm{SH}$ and carotid atherosclerosis. In a cohort of 21,342, Kim et al. (34) did not have identify any changes in the frequency of the development of carotid plaques in $\mathrm{SH}$ adults with thyroid dysfunction during a 5-year follow-up. The prevalence of carotid plaques at baseline was significantly different among the three groups $(56.6 \%$ for $\mathrm{SH}, 47.8 \%$ for euthyroid patients, $48.0 \%$ for subclinical hyperthyroidism; $p=0.012$ ). FT4 was not a significant risk factor for carotid plaque formation in either patients with $\mathrm{SH}(p=0.164)$ or with euthyroidism $(p=0.311)$. Univariable analysis showed that the cumulative incidence of carotid plaque formation throughout the follow-up was not significantly different between $\mathrm{SH}$ and euthyroid patients ( $p=0.281)$. Similarly, Almeida et al. (35) have suggested that mild $\mathrm{SH}$ with no related metabolic changes is not associated with increased cardiovascular risk, as reflected by CIMT. In particular, no differences in mean carotid IMT were identified between patients and controls $(p=0.904)$. Similar results were found when dividing the cohort into subgroups with serum TSH lower or higher than $8 \mathrm{mIU} / 1$, i.e. no differences in the lipid profile and in the apoprotein B and Lp(a) levels. Kim et al. (21) have studied the association between $\mathrm{SH}$ and CIMT and found that CIMT was significantly higher in patients with $\mathrm{SH}$ and overt hypothyroidism compared to euthyroid controls $(p<0.05)$. However, in a multivariate regression model that explained the variation in the CIMT, TSH and FT4 did not have a significant contribution to the CIMT, whereas other parameters, such as age, systolic blood pressure and LDL-cholesterol had.

As far as hyperthyroidism is concerned, Feng et al. (19) have evaluated the carotid artery wall-thickness in 180 female patients with Hashimoto thyroiditis, who were assigned to three groups on the basis of laboratory testing: i) hyperthyroidism, ii) hypothyroidism and iii) euthyroid. IMT was significantly higher in the hyperthyroidism group than in controls $(p<0.05)$ or the other groups $(p<0.05)$. Delitala et al. (4) have examined the association of subclinical thyroid dysfunctions with arterial thickening and plaque, including 5,815 subjects in their study. They concluded that thyroid hormone is not associated with increased IMT or with the presence of carotid artery plaque. Moreover, they didn't support the idea that treating subclinical disorders might help to prevent arterial remodeling and carotid atherosclerosis. Subclinical hyperthyroid patients showed greater IMT compared to euthyroid and SH subjects. Also, TSH was negatively correlated with IMT. Furthermore, the frequency of carotid plaques varied according to the thyroid function $(p=0.003)$, as it was higher among subclinical hyperthyroid patients

\section{Atherosclerosis and TSH association based on studies}

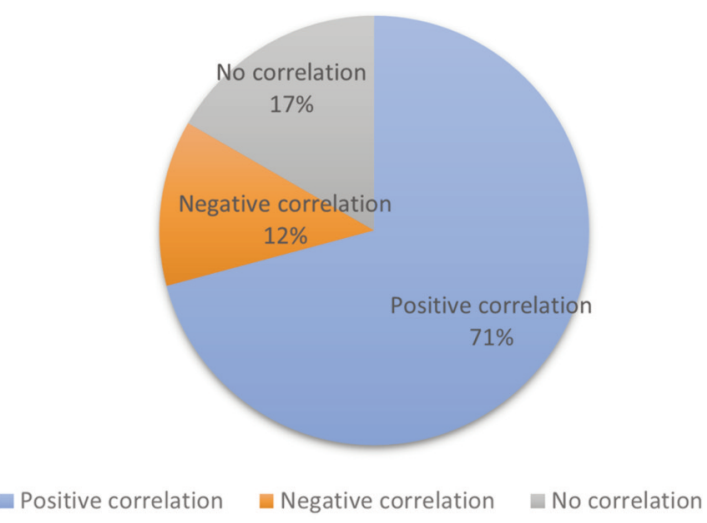

Figure 2. Association between atherosclerosis and thyroid dysfunction. TSH: Thyroid stimulating hormone.

compared to euthyroid and patients with SH. Volzke et al. (36) have investigated possible associations between thyroid dysfunction and carotid CIMT, including 29 participants with elevated serum TSH levels and 300 participants with decreased serum TSH levels. They found that higher IMT was observed in patients with hyperthyroidism and it was significantly lower in subjects with elevated serum TSH levels. The difference in IMT between euthyroid individuals and subjects with decreased serum TSH was also statistically significant. They concluded that there is an independent association between thyroid function and the IMT of the carotid artery $(p<0.01)$. In accordance with this, Jorde et al. (7) have measured the CIMT in 2,034 subjects, classified in three groups depending on their serum TSH. They concluded that, although subjects in the low serum TSH group had a higher mean IMT compared to those with normal and high serum TSH, the differences were not significant when adjusted for other characteristics (age, gender, smoking status, body mass index).

Table I summarizes the selected studies evaluating the effect of thyroid function on carotid artery atherosclerosis.

Effect of L-T4 replacement. Some studies associate thyroid hormone replacement and the consequent normalization of thyroid function with a reversal of endothelial dysfunction. In particular, Ghasemi et al. (26) have evaluated CIMT after normalization of thyroid function with L-thyroxine treatment for one year. After 12-14 months of thyroid function normalization, the mean CIMT decreased in SH patients significantly $(p<0.001)$. According to Monzani et al. (6), six months of stable thyroid function can lead to a significant decrease of mean-IMT. Although still slightly higher than in euthyroid controls $(p=0.056)$, mean-IMT of the L-T4 treated 
Table I. Studies that evaluate the effect of thyroid function on carotid artery atherosclerosis.

\begin{tabular}{|c|c|c|c|c|c|c|}
\hline Parameter & Author & Year & $\mathrm{N}$ & Subjects & Controls & $p$-Value \\
\hline IMT & Franzoni & 2007 & 72 & $0.6 \mathrm{~mm}$ & $0.8 \mathrm{~mm}$ & $<0.0001$ \\
\hline IMT & Feng & 2015 & 180 & $513 \mu \mathrm{m}$ & $513 \mu \mathrm{m}$ & $<0.05$ \\
\hline Stiffness & & & & 10.9 & 8.08 & $>0.05$ \\
\hline IMT & Volzke & 2004 & 2,086 & $0.831 \mathrm{~mm}$ & $0.841 \mathrm{~mm}$ & $>0.05$ \\
\hline ICS & Jeong & 2010 & 382 & $33.3 \%$ & $17.8 \%$ & 0.004 \\
\hline IMT & Monzani & 2004 & 77 & $0.75 \mathrm{~mm}$ & $0.63 \mathrm{~mm}$ & $<0.01$ \\
\hline IMT & Jorde & 2008 & 2034 & $0.84 \mathrm{~mm}$ & $0.84 \mathrm{~mm}$ & $>0.05$ \\
\hline $\begin{array}{l}\text { CAROTID } \\
\text { PLAQUES }\end{array}$ & Kim & 2017 & 21,342 & $55.6 \%$ & $47.8 \%$ & $<0.05$ \\
\hline IMT & Boskus & 2016 & 52 & $0.8 \mathrm{~mm}$ & $0.54 \mathrm{~mm}$ & 0.002 \\
\hline IMT & Peixoto & 2016 & 8623 & $0.6 \mathrm{~mm}$ & $0.56 \mathrm{~mm}$ & $<0.0001$ \\
\hline IMT & Knapp & 2012 & 55 & $0.64 \mathrm{~mm}$ & $0.32 \mathrm{~mm}$ & $<0.001$ \\
\hline IMT & Valentina & 2011 & 99 & $0.61 \mathrm{~mm}$ & $0.56 \mathrm{~mm}$ & 0.034 \\
\hline Carotid Plaques & & & & $10.1 \%$ & $3.3 \%$ & - \\
\hline Stiffness & Tian & 2010 & 183 & 9.83 & 7.54 & 0.022 \\
\hline IMT & Ghasemi & 2010 & 78 & - & - & 0.01 \\
\hline IMT & Saif & 2018 & 110 & $0.7 \mathrm{~mm}$ & $0.45 \mathrm{~mm}$ & $<0.001$ \\
\hline IMT & Kim & 2009 & 108 & $0.66 \mathrm{~mm}$ & $0.57 \mathrm{~mm}$ & $<0.05$ \\
\hline IMT & Cikim & 2004 & 61 & $0.55 \mathrm{~mm}$ & $0.54 \mathrm{~mm}$ & $>0.05$ \\
\hline IMT & Duman & 2007 & 60 & $0.66 \mathrm{~mm}$ & $0.54 \mathrm{~mm}$ & 0.0001 \\
\hline IMT & Nagasaki & 2004 & 60 & $0.63 \mathrm{~mm}$ & $0.54 \mathrm{~mm}$ & 0.004 \\
\hline Stiffness & & & & 9.46 & 8.02 & 0.047 \\
\hline IMT & Unal & 2017 & 76 & $0.5 \mathrm{~mm}$ & $0.4 \mathrm{~mm}$ & 0.001 \\
\hline IMT & Balci & 2016 & 84 & $0.48 \mathrm{~mm}$ & $0.43 \mathrm{~mm}$ & 0.001 \\
\hline
\end{tabular}

N: Sample size; SH: subclinical hypothyroidism; IMT: intima-media thickness; ICS: internal carotid artery steno-occlusion.

group was significantly lower $(p=0.03)$ compared to the placebo-treated group. Cikim et al. (28) have also found that LT4 therapy can lead to a significant reduction in IMT aFTer a 5-month stable euthyroid state. Nagasaki et al. (33) have examined the effect of L-T4 treatment on the two parameters mentioned above at least one year aFTer normalization of thyroid function. Mean arterial stiffness $\beta$-index and CIMT decreased significantly ( $p<0.05$ and $p<0.0001$, respectively). Moreover, both values did not differ significantly from those obtained for normal controls $(p=0.562$ and $p=0.897$, respectively). Duman et al. (29) have concluded that L-T4 replacement causes a significant reduction in IMT $(p=0.0001)$.

Other studies have yielded contradictory results. Blum et al. (37), in a double-blind, randomized, placebo-controlled trial of 185 elderly participants, have assessed the impact of $\mathrm{SH}$ treatment using levothyroxine on carotid atherosclerosis. After a median treatment of 18.4 months, mean CIMT did not differ significantly between the levothyroxine and the placebo group $(p=0.30)$. Additionally, the proportion of carotid plaque and maximum carotid plaque thickness were similar in the two groups. Kim et al. (21) have tried to determine whether thyroid hormone replacement can reverse the change in the CIMT. One year after achieving a euthyroid state, there was a significant decrease in the CIMT ( $p=0.021$ ); however, when the change in the CIMT was used as an dependent variable in multiple regression analysis, the absolute decrement of the CIMT was independently associated with the absolute reduction in LDL-cholesterol levels, but not with the reduction in TSH levels. Therefore, the regression of the increased CIMT after thyroid hormone replacement was attributed to the improvement of the lipid profile. Cabral et al. (3) have examined the effect of L-T4 replacement on endothelial function and CIMT in female patients with mild SH. The patients were randomly assigned to 12 months of L-T4 replacement or no treatment. The results did not show any correlation between the carotid IMT and the studied variables or a reduction of CIMT after one year of LT4 treatment. On the other hand, when users and non-users of thyroxine were compared in the study of Jorde et al. (7), patients on thyroxine had a significantly higher IMT $(p<0.01)$.

Table II summarizes the studies evaluating the effect of LT4 replacement on atherosclerosis.

\section{Discussion}

The association between thyroid dysfunction and abnormal IMT might be supported by many mechanistic studies in experimental and clinical settings. Hyperthyroidism induces peripheral vasodilatation, that in turn, results into decreased 
Bakoyiannis et al: Thyroid Dysfunction and Atherosclerosis (Review)

Table II. Studies that evaluate the effect of LT4 replacement on atherosclerosis. N: Sample size; IMT: intima-media thickness; L-T4: L-thyroxine.

\begin{tabular}{lcccccc}
\hline LT4 Therapy & Author & Year & $\mathrm{N}$ & Subjects & Controls & $p$-Value \\
\hline IMT & Monzani & 2004 & 77 & $0.67 \mathrm{~mm}$ & $0.77 \mathrm{~mm}$ & 0.03 \\
IMT & Jorde & 2008 & 2034 & $0.88 \mathrm{~mm}$ & $0.83 \mathrm{~mm}$ & $<0.01$ \\
IMT & Blue & 2018 & 185 & $0.85 \mathrm{~mm}$ & $0.83 \mathrm{~mm}$ & 0.3 \\
IMT & Cabral & 2011 & 32 & $0.66 \mathrm{~mm}$ & $0.67 \mathrm{~mm}$ & $>0.05$ \\
IMT & Ghasemi & 2010 & 78 & - & 0.001 \\
IMT & Kim & 2009 & 108 & $0.60 \mathrm{~mm}$ & $0.67 \mathrm{~mm}$ & 0.021 \\
IMT & Duman & 2007 & 60 & $0.55 \mathrm{~mm}$ & $0.65 \mathrm{~mm}$ & $<0.001$ \\
IMT & Nagasaki & 2004 & 60 & $0.55 \mathrm{~mm}$ & $0.63 \mathrm{~mm}$ & $<0.0001$ \\
Stiffness & & & 7.58 & 9.46 & 0.027 \\
\hline
\end{tabular}

renal perfusion and activation of the renin-angiotensin axis. The latter might lead to stimulation of vascular smooth muscle cell growth and matrix biosynthesis. Vascular hypertrophy is strongly linked to increased vascular resistance and stiffness $(15,30)$. Similar findings have been recently found in patients with Graves' disease $(38,39)$. Even if it is not fully elucidated whether additional mechanisms can provoke an increase in the thickness of arterial vessel wall in hyperthyroidism, an increased IMT probably reflects a homeostatic vascular wall response to changes in shear and tensile stress. Similar phenomena might be caused by hyperthyroidism via increased heart rate and pulse pressure (36).

The collected studies have assessed the relationship between thyroid dysfunction and a risk for atherosclerosis; however, they have yielded contradictory results, with some of them showing that hyper or hypothyroidism, overt or subclinical, can increase cardiovascular risk when other studies showing no such effect. This controversy may be attributed to study design heterogeneity and inherent limitations, including short follow-up periods, inclusion of patients in thyroid hormone replacement or medications that affect the lipid profile, or even heterogeneous causes of hypothyroidism. Heterogeneity in methodology, especially as far as IMT measurement and carotid artery evaluation is concerned, might be another source of bias on top of the small sample sizes and inconsistent ranges of normality of thyroid hormones (4). Of note, $\mathrm{SH}$ can improve or worsen during the follow-up period, thus, a single set of thyroid hormone levels could result in a false diagnosis of transient subclinical thyroid dysfunction, that in turn might confound the real effects of $\mathrm{SH}$ on carotid atherosclerosis. By excluding transient $\mathrm{SH}$ dysfunction, the effects of sustained $\mathrm{SH}$ on carotid atherosclerosis can be assessed more accurately (34).

Whether L-T4 replacement can decrease the cardiovascular risk or even inhibit the progression of vascular wall lesions in SH is still under debate, as illustrated by the contradictory results of the reviewed studies. The interpretation of the results is dependent on the effectiveness of each treatment. The latter has implications on the interpretation of the optimal values for TSH in patients with $\mathrm{SH}$ under L-T4 replacement treatment. According to the literature, these optimal values are unclear. As shown in some studies, it is not uncommon for patients in clinical trials to be outside the therapeutic target by the end of the study period as these values define (3). Moreover, in patients on substitution therapy it is not easy to achieve TSH target since it is unlikely to reliably reproduce the fluctuating endogenous production of thyroid hormones (40). Similarly, some of the subjects on thyroxine might be undertreated, possibly leading to a higher IMT. Interestingly, subjects overtreated may also present with an increased IMT (7). Other potential explanation for the negative findings may be the lack of between-group differences in cardiovascular risk factors, including LDL cholesterol levels (41). Finally, underlying diseases necessitating substitution therapy with thyroxine, such as autoimmune hypothyroidism or hypothyroidism following treatment for thyroid nodular disease or Graves' disease, may also predispose for cardiovascular disease (7), which cannot be prevented or reversed by thyroxine (42).

It is also remarkable that IMT measurements vary among some studies. This can be due to many reasons. Firstly, the predictive value of IMT for atherosclerosis is dependent on the measurement technique. Since IMT calculation includes both the intimal and the medial layer, medial hypertrophy due to thyroid dysfunction can affect the results. For example, increased IMT in the common carotid artery, where blood flow is laminar, may be more reflective of a medial hypertrophy than of true intimal atherosclerosis (36). Secondly, many studies might have included plaques in the measurements of IMT, especially if these were located in areas predefined for IMT measurement. Thirdly, differences among IMT measurements could be due to other determinants of the IMT thickness, such as mean cholesterol, hypertension or age (19). IMT increases linearly with age even in subjects without atherosclerotic disease, probably as 
a reflection of senescence-related inflammation. Even if they are distinct entities, atherosclerosis and aging-induced arterial remodeling seem to respond to the same biochemical, inflammatory and metabolic factors and should be considered closely related (43-46).

Another fact that is worth mentioning is that the majority of authors have examined the effect between TSH and cardiovascular risk and not FT3 or FT4. Contrary to serum TSH levels, serum FT3 and FT4 levels are less sensitive and specific in diagnosing thyroid dysfunction (28) since critical illness and medication can affect these levels. Also, solitary measurements of serum FT3 and FT4 are not sufficient to establish the diagnosis of SH. This could potentially explain why the thyroid function index and TSH groups, but not FT3 and FT4, were independently associated with IMT (35).

In conclusion, most of the collected studies correspond with the fact that thyroid dysfunction is associated with arterial wall remodeling and, thus, with an increased cardiovascular risk, while others object to this finding. These diverging observations are hard to reconcile and the relation between thyroid disorders and pathological structural changes of the arterial wall is, therefore, still unsettled. As a result, further large randomized controlled studies are required to definitively assess this relation and the extent to which T4 replacement therapy might benefit patients with subclinical thyroid disorders.

\section{Conflicts of Interest}

The Authors declare no conflicts of interest.

\section{Authors' Contributions}

AMP and NB contributed to the design and implementation of the research; AMP, NB, IS and DM contributed to the analysis of the results and to the writing of the manuscript, and CB supervised and critically revised the manuscript.

\section{References}

1 Franzoni F, Galetta F, Fallahi P, Tocchini L, Braccini L, Rossi M, Carpi A, Santoro G and Antonelli A: Carotid integrated backscatter analysis in patients with subclinical hypothyroidism. Clin Endocrinol (Oxf) 68(2): 278-283, 2007. PMID: 17803707. DOI: $10.1111 / \mathrm{j} .1365-2265.2007 .03035 . x$

2 Knapp M, Lisowska A, Sobkowicz B, Tycińska A, Sawicki R and Musiał WJ: Myocardial perfusion and intima-media thickness in patients with subclinical hypothyroidism. Adv Med Sci 58(1): 44-49, 2013. PMID: 23640950. DOI: 10.2478/ v10039-012-0068-9

3 Cabral MD, Teixeira P, Soares D, Leite S, Salles E and Waisman M: Effects of thyroxine replacement on endothelial function and carotid artery intima-media thickness in female patients with mild subclinical hypothyroidism. Clinics (Sao Paulo) 66(8): 1321-1328, 2011. PMID: 21915478. DOI: 10.1590/s180759322011000800003
4 Delitala AP, Filigheddu F, Orrù M, AlGhatrif M, Steri M, Pilia MG, Scuteri A, Lobina M, Piras MG, Delitala G, Lakatta EG, Schlessinger D and Cucca F: No evidence of association between subclinical thyroid disorders and common carotid intima medial thickness or atherosclerotic plaque. Nutr Metab Cardiovasc Dis 25(12): 1104-1110, 2015. PMID: 26615224. DOI: 10.1016/j.numecd.2015.09.001

5 Jeong SK, Seo JY, Nam HS and Park HK: Thyroid function and internal carotid artery stenosis in ischemic stroke. Endocr $\mathbf{J}$ 57(8): 711-718, 2010. PMID: 20647640. DOI: 10.1507/endocrj. k10e-135

6 Monzani F, Caraccio N, Kozàkowà M, Dardano A, Vittone F, Virdis A, Taddei S, Palombo C and Ferrannini E: Effect of levothyroxine replacement on lipid profile and intima-media thickness in subclinical hypothyroidism: a double-blind, placebo- controlled study. J Clin Endocrinol Metab 89(5): 20992106, 2004. PMID: 15126526. DOI: 10.1210/jc.2003-031669

7 Jorde R, Joakimsen O, Stensland E and Mathiesen EB: Lack of significant association between intima-media thickness in the carotid artery and serum TSH level. The Troms $\varnothing$ Study. Thyroid 18(1): 21-25, 2008. PMID: 17985996. DOI: 10.1089/thy.2007.0165

8 Perk J, De Backer G, Gohlke H, Graham I, Reiner Z, Verschuren M, Albus C, Benlian P, Boysen G, Cifkova R, Deaton C, Ebrahim S, Fisher M, Germano G, Hobbs R, Hoes A, Karadeniz S, Mezzani A, Prescott E, Ryden L, Scherer M, Syvänne M, Scholte op Reimer WJ, Vrints C, Wood D, Zamorano JL and Zannad F: European Association for Cardiovascular Prevention \& Rehabilitation (EACPR); ESC Committee for Practice Guidelines (CPG): European Guidelines on cardiovascular disease prevention in clinical practice (version 2012). The Fifth Joint Task Force of the European Society of Cardiology and Other Societies on Cardiovascular Disease Prevention in Clinical Practice (constituted by representatives of nine societies and by invited experts). Eur Heart J 33(13): 1635-1701, 2012. PMID: 22555213. DOI: 10.1093/eurheartj/ehs092

9 Goff DC Jr, Lloyd-Jones DM, Bennett G, Coady S, D'Agostino RB, Gibbons R, Greenland P, Lackland DT, Levy D, O'Donnell CJ, Robinson JG, Schwartz JS, Shero ST, Smith SC Jr, Sorlie P, Stone NJ, Wilson PW, Jordan HS, Nevo L, Wnek J, Anderson JL, Halperin JL, Albert NM, Bozkurt B, Brindis RG, Curtis LH, DeMets D, Hochman JS, Kovacs RJ, Ohman EM, Pressler SJ, Sellke FW, Shen WK, Smith SC Jr and Tomaselli GF: 2013 ACC/AHA guideline on the assessment of cardiovascular risk: a report of the American College of Cardiology/American Heart Association Task Force on Practice Guidelines. American College of Cardiology/American Heart Association Task Force on Practice Guidelines. Circulation 129(25): 49-73, 2014. PMID: 24222018. DOI: 10.1161/01.cir.0000437741.48606.98

10 Darabian S, Hormuz M, Latif MA, Pahlevan S and Budoff MJ: The role of carotid intimal thickness testing and risk prediction in the development of coronary atherosclerosis. Curr Atheroscler Rep 15(3): 306, 2013 PMID: 23328906. DOI: 10.1007/s11883012-0306-4

11 Stamatouli A, Bedoya P and Yavuz S: Hypothyroidism: Cardiovascular endpoints of thyroid hormone replacement. Front Endocrinol (Lausanne) 10: 888, 2020. PMID: 31998229. DOI: 10.3389/fendo.2019.00888

12 Shirwany NA and Zou MH: Arterial stiffness: a brief review. Acta Pharmacol Sin 31(10): 1267-1276, 2010. PMID: 20802505. DOI: $10.1038 /$ aps.2010.123 
13 Bozkus F, Dikmen N, Güngör G and Samur A: The effect of obstructive sleep apnea syndrome and hypothyroidism to intimamedia thickness of carotid artery. Sleep Breath 21(1): 31-36, 2017. PMID: 27438724. DOI: 10.1007/s11325-016-1384-2

14 Biondi B and Klein I: Hypothyroidism as a risk factor for cardiovascular disease. Endocrine 24(1): 1-13, 2004 PMID: 15249698. DOI: 10.1385/ENDO:24:1:001

15 Peixoto de Miranda ÉJ, Bittencourt MS, Pereira AC, Goulart AC, Santos IS, Lotufo PA and Bensenor IM: Subclinical hypothyroidism is associated with higher carotid intima-media thickness in cross-sectional analysis of the Brazilian Longitudinal Study of Adult Health (ELSA-Brasil). Nutr Metab Cardiovasc Dis 26(10): 915-921, 2016. PMID: 27389191. DOI: 10.1016/j.numecd.2016.06.005

16 Unal E, Akın A, Yıldırım R, Demir V, Yildiz İ and Haspolat YK: Association of subclinical hypothyroidism with dyslipidemia and increased carotid intima-media thickness in children. J Clin Res Pediatr Endocrinol 9(2): 144-149. PMID: 280088622017. DOI: $10.4274 /$ jcrpe. 3719

17 Rizos CV, Elisaf MS and Liberopoulos EN: Effects of thyroid dysfunction on lipid profile. Open Cardiovasc Med J 5: 76-84, 2011. PMID: 21660244. DOI: 10.2174/1874192401105010076

18 Milionis HJ, Tambaki AP, Kanioglou CN, Elisaf MS, Tselepis $\mathrm{AD}$ and Tsatsoulis A: Thyroid substitution therapy induces highdensity lipoprotein-associated platelet-activating factoracetylhydrolase in patients with subclinical hypothyroidism: a potential antiatherogenic effect. Thyroid 15(5): 455-460, 2005. PMID: 15929667. DOI: 10.1089/thy.2005.15.455

19 Feng X, Zhao L, Jiang J, Ma W, Shang X, Zhou Q, Zhang H, Yu $S$ and Qi Y: Discriminatory value of carotid artery elasticity changes for the evaluation of thyroid dysfunction in patients with hashimoto's thyroiditis. J Clin Ultrasound 44(5): 298-304, 2016. PMID: 26856968. DOI: $10.1002 /$ jcu. 22328

20 Mizuma H, Murakami M and Mori M: Thyroid hormone activation in human vascular smooth muscle cells: expression of type II iodothyronine deiodinase. Circ Res 88(3): 313-318, 2001. PMID: 11179199. DOI: 10.1161/01.res.88.3.313

21 Kim SK, Kim SH, Park KS, Park SW and Cho YW: Regression of the increased common carotid artery-intima media thickness in subclinical hypothyroidism after thyroid hormone replacement. Endocr J 56(6): 753-758, 2009. PMID: 19506325. DOI: 10.1507/endocrj.k09e-049

22 Taddei S, Caraccio N, Virdis A, Dardano A, Versari D, Ghiadoni L, Ferrannini E, Salvetti A and Monzani F: Low-grade systemic inflammation causes endothelial dysfunction in patients with Hashimoto's thyroiditis. J Clin Endocrinol Metab 91(12): 50765082, 2006. PMID: 16968790. DOI: 10.1210/jc.2006-1075

23 Kvetny J, Heldgaard PE, Bladbjerg EM and Gram J: Subclinical hypothyroidism is associated with a low-grade inflammation, increased triglyceride levels and predicts cardiovascular disease in males below 50 years. Clin Endocrinol (Oxf) 61(2): 232-238, 2004. PMID: 15272919. DOI: 10.1111/j.1365-2265.2004.02088.x

24 Tan M, Korkmaz H, Aydın H and Kumbul Doğuç D: FABP4 levels in hypothyroidism and its relationship with subclinical atherosclerosis. Turk J Med Sci 49(5): 1490-1497, 2019. PMID: 31651119. DOI: $10.3906 /$ sag-1904-41

25 Valentina VN, Marijan B, Chedo D and Branka K: Subclinical hypothyroidism and risk to carotid atherosclerosis. Arq Bras Endocrinol Metabol 55(7): 475-80, 2011. PMID: 22147096. DOI: $10.1590 / \mathrm{s} 0004-27302011000700007$
26 Ghasemi M, Mousavi SA, Rezvanian H, Asadi B, Khorvash F and Fatehi F: Carotid intima-media thickness in subclinical hypothyroidism. Int J Stroke 5(2): 131-132, 2010. PMID: 20446948. DOI: 10.1111/j.1747-4949.2010.00417.x

27 Saif A, Mousa S, Assem M, Tharwat N and Abdelhamid A: Endothelial dysfunction and the risk of atherosclerosis in overt and subclinical hypothyroidism. Endocr Connect. 7(10): 10751080, 2018. PMID: 30352390. DOI: 10.1530/EC-18-0194

28 Cikim AS, Oflaz H, Ozbey N, Cikim K, Umman S, Meric M, Sencer E and Molvalilar S: Evaluation of endothelial function in subclinical hypothyroidism and subclinical hyperthyroidism. Thyroid 14(8): 605-609, 2004. PMID: 15320973. DOI: 10.1089/ 1050725041692891

29 Duman D, Demirtunc R, Sahin S and Esertas K: The effects of simvastatin and levothyroxine on intima-media thickness of the carotid artery in female normolipemic patients with subclinical hypothyroidism: a prospective, randomized-controlled study. J Cardiovasc Med (Hagerstown) 8(12): 1007-1011, 2007. PMID: 18163011. DOI: 10.2459/JCM.0b013e3282f03bc1

30 Isik-Balci Y, Agladioglu S, Agladioglu K, Kilic-Toprak E, KilicErkek O, Ozhan B, Polat A and Bor-Kucukatay M: Impaired hemorheological parameters and increased carotid intima-media thickness in children with subclinical hypothyroidism. Horm Res Paediatr 85(4): 250-256, 2016. PMID: 26934063. DOI: 10.1159/ 000444363

31 Sevuk U, Bahadir MV, Altindag R, Baysal E, Altintas B, Yaylak B, Adiyaman MS and Ay N: Relationship between thyroid function and carotid artery plaque ulceration. Acta Neurol Belg 115(4): 581-587, 2015. PMID: 25672265. DOI: 10.1007/s13760$015-0435-y$

32 Tian L, Gao C, Liu J and Zhang X: Increased carotid arterial stiffness in subclinical hypothyroidism. Eur J Intern Med 21(6): 560-563, 2010. PMID: 21111945. DOI: 10.1016/j.ejim.2010. 08.005

33 Nagasaki T, Inaba M, Kumeda Y, Ueda M, Hiura Y, Tahara H, Ishimura E, Onoda N, Ishikawa T and Nishizawa Y: Decrease of arterial stiffness at common carotid artery in hypothyroid patients by normalization of thyroid function. Biomed Pharmacother 59(1-2): 8-14, 2005. PMID: 15740929. DOI: 10.1016/j.biopha.2004.11.001

34 Kim H, Kim TH, Kim HI, Park SY, Kim YN, Kim S, Kim MJ, Jin SM, Hur KY, Kim JH, Lee MK, Min YK, Chung JH, Kang $\mathrm{M}$ and Kim SW: Subclinical thyroid dysfunction and risk of carotid atherosclerosis. PLoS One 12(7): e0182090, 2017. PMID: 28750042. DOI: 10.1371/journal.pone.0182090

35 Almeida CA, Teixeira Pde F, Soares DV, Cabral MD, Costa SM, Salles EF, O E Silva NA, Morais FF, Buescu A, Henriques $\mathrm{JM}$ and Vaisman M: Carotid intima-media thickness as a marker of cardiovascular risk in patients with subclinical hypothyroidism. Arq Bras Endocrinol Metabol 51(3): 472-477, 2007. PMID: 17546248. DOI: 10.1590/s0004-27302007000 300017

36 Völzke H, Robinson DM, Schminke U, Lüdemann J, Rettig R, Felix SB, Kessler C, John U and Meng W: Thyroid function and carotid wall thickness. J Clin Endocrinol Metab 89(5): 21452149, 2004. PMID: 15126533. DOI: 10.1210/jc.2003-031028

37 Blum MR, Gencer B, Adam L, Feller M, Collet TH, da Costa BR, Moutzouri E, Dopheide J, Depairon M, Sykiotis GP, Kearney P, Gussekloo J, Westendorp R, Stott DJ, Bauer DC and Rodondi N: Impact of thyroid hormone therapy on 
atherosclerosis in the elderly with subclinical hypothyroidism: A randomized trial. J Clin Endocrinol Metab 103(8): 2988-2997, 2018. PMID: 29846630. DOI: 10.1210/jc.2018-00279.

38 Inaba M, Henmi Y, Kumeda Y, Ueda M, Nagata M, Emoto M, Ishikawa T, Ishimura $\mathrm{E}$ and Nishizawa Y: Increased stiffness in common carotid artery in hyperthyroid Graves' disease patients. Biomed Pharmacother 56(5): 241-246, 2002. PMID: 12199623. DOI: $10.1016 / \mathrm{s} 0753-3322(02) 00195-6$

39 Czarkowski M, Hilgertner L, Powałowski T and Radomski D: The stiffness of the common carotid artery in patients with Graves' disease. Int Angiol 21(2): 152-157, 2002. PMID: 12110776.

40 Pacini F, Schlumberger M, Dralle H, Elisei R, Smit JW, Wiersinga W; European Thyroid Cancer Taskforce: European consensus for the management of patients with differentiated thyroid carcinoma of the follicular epithelium. Eur J Endocrinol 154(6): 787-803, 2006. PMID: 16728537. DOI: 10.1530/eje.1.02158

41 Rugge JB, Bougatsos C and Chou R: Screening and treatment of thyroid dysfunction: an evidence review for the U.S. Preventive Services Task Force. Ann Intern Med 162(1): 35-45, 2015. PMID: 25347444. DOI: 10.7326/M14-1456

42 Jonklaas J, Bianco AC, Bauer AJ, Burman KD, Cappola AR, Celi FS, Cooper DS, Kim BW, Peeters RP, Rosenthal MS and Sawka AM; American Thyroid Association Task Force on Thyroid Hormone Replacement: Guidelines for the treatment of hypothyroidism: prepared by the American thyroid association task force on thyroid hormone replacement. Thyroid 24(12): 16701751, 2014. PMID: 25266247. DOI: 10.1089/thy.2014.0028

43 Baldassarre D, Nyyssönen K, Rauramaa R, de Faire U, Hamsten A, Smit AJ, Mannarino E, Humphries SE, Giral P, Grossi E, Veglia F, Paoletti R and Tremoli E; IMPROVE study group: Cross-sectional analysis of baseline data to identify the major determinants of carotid intima-media thickness in a European population: the IMPROVE study. Eur Heart J 31(5): 614-622, 2010. PMID: 19952003. DOI:10.1093/eurheartj/ehp496
44 Moris D, Spartalis M, Spartalis E, Karachaliou GS, Karaolanis GI, Tsourouflis G, Tsilimigras DI, Tzatzaki E and Theocharis S: The role of reactive oxygen species in the pathophysiology of cardiovascular diseases and the clinical significance of myocardial redox. Ann Transl Med 5(16): 326, 2017. PMID: 28861423. DOI: 10.21037/atm.2017.06.27

45 Papapetrou A, Moris D, Patelis N, Kouvelos GN, Bakogiannis C, Klonaris C and Georgopoulos S: Oxidative stress and total antioxidant status during internal carotid artery clamping with or without shunting: An experimental pilot study. Med Sci Monit Basic Res 21: 200-205, 2015. PMID: 26391530. DOI: 10.12659/ MSMBR.894756

46 Makris S, Venetsanou K, Spartalis E, Kontogiannis C, Georgiopoulos G, Spartalis M, Tsilimigras DI, Moris D, Kakisis I, Karaolanis G, Patelis N, Zymvragoudakis V, Papasilekas TI, Themistoklis KM and Lazaris A: Changes in serum leptin levels as well as sICAM-1 and sVCAM-1 soluble adhesion molecules during carotid endarterectomy. Eur Rev Med Pharmacol Sci 23(5): 2257-2262, 2019. PMID: 30915774. DOI: 10.26355/ eurrev_201903_17274

Received September 3, 2020

Revised September 23, 2020

Accepted September 25, 2020 